\title{
Early Left Ventricular Systolic Dysfunction Detected by Two-Dimensional Speckle-Tracking Echocardiography in Young Patients with Congenital Generalized Lipodystrophy
}

This article was published in the following Dove Press journal:

Diabetes, Metabolic Syndrome and Obesity: Targets and Therapy

Christiane Bezerra Rocha Liberato, (iD ${ }^{1,2}$ Natália Bitar da Cunha Olegario, (iD) ${ }^{1,2}$ Virginia Oliveira Fernandes, (iD) ${ }^{1-3}$ Ana Paula Dias Rangel Montenegro, ${ }^{2}$ Grayce Ellen da Cruz Paiva Lima, (iD) ${ }^{1,2}$ Lívia Aline de Araújo Batista, (ID) ${ }^{1,2}$ Lívia Vasconcelos Martins, (iD) ${ }^{1,2}$ Jaquellyne Gurgel Penaforte-Saboia, (iD) I,2 Ivan Lucas Rocha Liberato, ${ }^{2}$ Larissa Ferreira Lopes, (D) ${ }^{2}$ Catarina Brasil d'Alva, ${ }^{1,2}$ Frederico Luís Braz Furtado, (iD) 1,2 Ricardo Luiz De Medeiros Lima, ${ }^{4}$ Lucia Helena Coelho Nóbrega, (iD ${ }^{4}$ Josivan Gomes Lima, ${ }^{4}$ Renan Magalhães Montenegro Junior (iD) ${ }^{1-3}$

Brazilian Group for the Study of Inherited and Acquired Lipodystrophies (BRAZLIPO)

'Department of Clinical Medicine, Federal University of Ceará, Fortaleza, Brazil; ${ }^{2}$ Clinical Research Unit, Walter Cantidio University Hospital, Federal University of Ceará, Fortaleza, Brazil; ${ }^{3}$ Department of Community Health, Federal University of Ceará, Fortaleza, Brazil; ${ }^{4}$ Department of Clinical Medicine, Onofre Lopes University Hospital, Federal University of Rio Grande do Norte, Natal, Rio Grande do Norte, Brazil
Correspondence: Renan Magalhães Montenegro Junior Rua Professor Costa Mendes, 1608,

Fortaleza, Ceará 60416-200, Brazil

Tel $+55853366-8600$

Fax +55853366-8619

Email renanmmjr@gmail.com
Purpose: Congenital generalized lipodystrophy (CGL) is a rare autosomal recessive disorder characterized by the absence of functional adipocytes resulting in ectopic lipid storage, metabolic disorders and early cardiovascular disease. Two-dimensional speckle-tracking (2D-STE) allows the detection of early abnormalities in myocardial function. We aimed to evaluate myocardial deformation in a large sample of CGL patients using 2D-STE.

Patients and Methods: A cross-sectional study of 22 patients with CGL and 22 healthy subjects, matched for sex and age, was conducted from 2013 to 2018. All participants had undergone standard conventional echocardiography (ECHO) and 2D-STE. Determination of blood glucose, lipids, insulin, and leptin were performed in all CGL patients.

Results: In the CGL group the mean age was $14.6 \pm 10.7$ years where $68.2 \%(n=15)$ were younger than 18 years old. All the patients had hypoleptinemia, 95.4\% (21/22) low HDL-c, 86.4\% (19/22) hypertriglyceridemia, $68.2 \%(15 / 22)$ diabetes, 50\% (11/22) hepatic steatosis, $41 \%(9 / 22)$ insulin resistance, $41 \%$ (9/22) hypercholesterolemia, and 18.2\% (4/22) hypertension. ECHO showed that $36.6 \%(8 / 22)$ of CGL patients presented diastolic dysfunction, 31.8\% (7/22) left ventricular hypertrophy (LVH), 27.3\% (6/22) increased left atrial volume index (LAVI), and 18.2\% (4/22) increased left ventricular systolic diameter (LVDS) but normal ejection fraction (EF), whether using 2D-STE, $68.2 \%$ (15/22) of CGL patients showed abnormal global longitudinal strain (GLS) $(\mathrm{p}<0.01)$, and in almost LV segments. Positive association between abnormal GLS and Alc $(r=0.57, p=0.005)$, glucose $(r=0.5, p=0.018)$ and basal insulin $(r=0.69, p=0.024)$, and negative association with leptin $(\mathrm{r}=-0.51, \mathrm{p}=0.005)$ were found in these patients.

Conclusion: The 2D-STE revealed precocious left ventricular systolic dysfunction in a young CGL population with normal systolic function by ECHO. Early exposure to common metabolic abnormalities as insulin resistance, hyperglycemia, and hypoleptinemia must be involved in myocardial damage in these patients.

Keywords: Berardinelli-Seip congenital lipodystrophy, global longitudinal strain, cardiac function, early detection

\section{Introduction}

Congenital Generalized Lipodystrophy (CGL) is a rare autosomal recessive disease with a higher incidence in countries such as Lebanon, Portugal, Oman and Brazil. The absence of subcutaneous adipose tissue since birth or early childhood and consequent impairment of normal fat deposition lead to precocious ectopic lipid accumulation in tissues such as muscle, liver, heart and arterial wall. Consequently, 
there are severe and precocious metabolic abnormalities as insulin resistance, diabetes mellitus, hepatic steatosis and premature atherosclerotic disease, which may lead to early cardiovascular mortality. 1,2

Cardiomyopathy, heart failure, systemic arterial hypertension, myocardial infarction, arrhythmias and sudden death have been described in CGL. ${ }^{3-5}$ The evaluation of heart morphology and function in this population has been performed by conventional echocardiography (ECHO). Although ECHO is the most common approach for assessing left ventricular (LV) systolic function mainly based on ejection fraction (EF), this is limited in detecting subtle abnormalities in myocardial contraction. ${ }^{6}$

Two-dimensional speckle-tracking echocardiography (2DSTE) is a new echocardiography technique that plays an important role in early detection of cardiac dysfunction, and more sensitive than EF to evaluate LV systolic function. ${ }^{7-11}$ The 2D-STE measures myocardial deformation through the measurement of global longitudinal strain (GLS), global circumferential strain (GCS) or global radial strain (GRS). ${ }^{6,10}$

Few studies have assessed cardiac function in patients with CGL, mainly case reports, and none using 2D-STE. ${ }^{3,12-17}$ Thus, the aim of this study was to assess myocardial deformation and detect preclinical myocardial dysfunction using 2DSTE echocardiography in a large sample of patients with generalized congenital lipodystrophy.

\section{Materials and Methods Study Population}

This is a cross-sectional study of CGL patients from Ceará, Northeast of Brazil, conducted from January 2013 to December 2018. Patients were followed up by a multidisciplinary team of the regional reference center of the Brazilian Group for the Study of Inherited and Acquired Lipodystrophies (BRAZLIPO).

The current study is reported according to the Strengthening the Reporting of Observational Studies in Epidemiology (STROBE) statement. ${ }^{18}$

The inclusion criteria were CGL diagnosed according to the clinical criteria by Patni e Garg. ${ }^{19}$ Exclusion criteria were: unstable sinus rhythm, conduction and rhythm disorders, and poor acoustic windows. Patients who did not complete the study protocol were excluded.

The control group consisted of healthy and eutrophic individuals matched 1:1 according to age and gender. Healthy individuals were those without diabetes or any other metabolic disease, did not use any medication, and did not present any episode of infection or hospitalization in the last month. Exclusion criteria were the same used for the group of patients.

\section{Clinical and Biochemical Analysis}

Clinical history was assessed through medical records, and physical examination and anthropometric measurements were performed on all the participants. In CGL group, biochemical tests were carried out after a $12 \mathrm{hr}$ fasting to determine blood glucose, total cholesterol, HDL-cholesterol, triglycerides, glycohemoglobin A1c (A1c), basal insulin and leptin. The homeostasis model assessment of insulin resistance (HOMA-IR) was calculated in patients who did not use exogenous insulin. ${ }^{20}$ Genetic testing was performed according to the previous study. ${ }^{21}$

\section{Echocardiography Analysis}

Standard transthoracic echocardiography study was performed using Vivid 7 and Vivid 9 (GE Medical Systems, Milwaukee, Wisconsin ${ }^{\circledR}$, USA) ultrasound machines with a $3.5-\mathrm{MHz}$ transducer for harmonic imaging following the criteria established by the American Society of Echocardiography. ${ }^{22-25}$

\section{Conventional Echocardiography}

The values of all conventional ECHO parameters were calculated as the average value of three consecutive cardiac cycles. LV end-systolic and end-diastolic diameters, LV posterior wall and interventricular septum thickness were measured using the two-dimensional echocardiography guided M-mode method. Measurements were analyzed according to the reference values; therefore, the participants were divided into age groups: children and adolescents ( $<18$ years of age) and adults ( $\geq 18$ years of age). ${ }^{26}$ Left ventricle ejection fraction (LVEF) was estimated using the Simpson method. LV mass was calculated using the Devereaux formula and indexed to the height in children and adolescents ${ }^{2,8}$ and to the body surface area (BSA) in adults. ${ }^{26-28}$

Pulsed-wave Doppler (PW) was used to measure mitral inflow velocities, peak early $(\mathrm{E})$ and late $(\mathrm{A})$ diastolic velocities, the E/A ratio, and the E-wave deceleration time. The early diastolic velocity (E') of the mitral annulus was measured at the lateral (El) and septal (Es) sites of the mitral annulus using pulsed-wave Doppler tissue imaging (DTI). The average E' value (lateral and septal sites) was used to calculate the E/E' ratio. ${ }^{29}$ Left atrial volume (LAV) was calculated using the biplane disk summation technique and then 
indexed to the BSA. ${ }^{30}$ In addition, Color Doppler flow imaging was used for mapping valvar regurgitation.

\section{Speckle Tracking Echocardiography}

To obtain specific 2D images using STE, digital loops with three successive cardiac cycles were acquired from LV apical 2chamber (2C), 3-chamber (3C) and 4-chamber (4C) views. The frame rate for these recordings was set at 60 to 90 frames/s. ${ }^{31,32}$ After selecting the best-quality two-dimensional image of the cardiac cycle, the LV endocardial border was manually traced at the end-systolic frame. After that, a speckle-tracking region of interest was automatically selected to approximate the myocardium between the endocardium and epicardium. The width of the region of interest was adjusted as necessary to accommodate the total thickness of the LV wall. The LV was divided into 18 segments: 3 levels (basal, mid-cavity and apical), which were further divided into 6 segments (anterior, posterior, lateral, inferior, septal, and anteroseptal). Longitudinal strains for each individual segment were measured and expressed as a bull'seye, and the software calculated GLS by averaging local strains along the entire LV. ${ }^{33,34}$ More negative strain values represent an increased contraction of the myocardium. Normal values of GLS were stratified by age distribution (years) according to references ranges. ${ }^{30,35}$

\section{Statistical Analysis}

Data were analyzed using the Statistical Package for the Social Sciences (SPSS) version 17.0 (GraphPad Software Inc., San Diego, CA, USA). Descriptive analysis was presented in tables with frequency and percentage for categorical variables and mean and standard deviation for numerical variables. Fisher's exact test, Pearson's chi-squared test and Spearman correlation coefficient were used to check for associations between the studied variables. Student's $t$-test or MannWhitney test were used to compare means. The normality of data was tested using the Shapiro-Wilk test. A p-value $<0.05$ was considered statistically significant.

\section{Results}

\section{Clinical and Metabolic Characteristics of the CGL Group}

Twenty-two patients with a clinical diagnosis of CGL were evaluated. The mean age was $14.6 \pm 10.7$ years, $68.2 \%(15 / 22)$ were younger than 18 years old, and $59 \%$ (13/22) were women. The mean age of participants in the group $<18$ years was $8.3 \pm$ 4.7 years, and in the group $\geq 18$ years was $28.0 \pm 6.2$ years. The mean age at CGL diagnosis was $7.4 \pm 11.1$ years, ranging from 1 month to 38 years of age. All the patients had hypoleptinemia, 95.4\% (21/22) had low HDL-c, 86.4\% (9/22) had hypertriglyceridemia, $68.2 \%$ (15/22) diabetes, $50 \%$ (11/22) hepatic steatosis, $41 \% \quad(9 / 22) \quad$ insulin resistance, $41 \% \quad(9 / 22)$ hypercholesterolemia, and $18.2 \%$ (4/22) hypertension. Genetic analysis was performed in only $45.4 \%$ (10/22) of the patients. AGPAT2 and BSCL2 gene mutations were identified in $40 \%$ (4/ $10)$ and $60 \%(6 / 10)$ of them, respectively.

\section{Conventional Echocardiographic Assessment of the CGL and Control Groups}

In CGL group, 32\% (7/22) presented left ventricular hypertrophy (LVH), 27.3\% (6/22) had increased left atrial volume index (LAVI), 18.2\% (4/22) had increased LV endsystolic diameter (LVDS) and 4.5\% (1/22) had increased LV end-diastolic diameter (LVDD).

Patients with CGL had increased LAVI $(\mathrm{p}<0.01)$ and increased left ventricular mass index (LVMI) compared to the control group $(\mathrm{p}<0.01)$. LVEF was normal in all participants. Diastolic function was abnormal in $36.6 \%(8 / 22)$ in CGL group, and normal in the control group. The velocities of E, Es and El waves were significantly lower in the CGL patients $\geq 18$ years of age than the control group (Table 1).

There were few morphological valve abnormalities in CGL patients. Mild mitral valvar regurgitation was detected in $18.2 \%$ (4/22) using Doppler color flow imaging in CGL group. Few CGL patients presented mild tricuspid regurgitation (3/22), and mild aortic regurgitation (1/22). All these patients were women and $75 \%(3 / 4)$ were aged $<18$ years.

\section{Global Longitudinal Strain of the CGL and Control Groups}

The 2D-STE detected abnormal GLS in $68.2 \%(15 / 22)$ of CGL patients. The proportion of CGL patients with abnormal GLS according to the age range is shown in Table 2. These alterations were not observed in the control group $(\mathrm{p}<0.01)$. Considering the genotype, patients with CGL2 (BCLS2 mutation) presented a higher prevalence of abnormal GLS than CGL1 (AGPAT2 mutation): $83.3 \%(5 / 6)$ versus $50 \%(2 / 4)$, respectively.

\section{Segmental Longitudinal Strain of CGL Patients and Control Group}

Compared to the control group, CGL patients presented impairment in GLS and in LV segmental longitudinal 
Table I Conventional Echocardiographic of 22 Patients with Congenital Generalized Lipodystrophy (CGL) and 22 Control Subjects According to the Age

\begin{tabular}{|c|c|c|c|c|c|c|}
\hline \multirow{2}{*}{$\begin{array}{l}\text { Age Group } \\
\text { ECHO }\end{array}$} & \multicolumn{3}{|c|}{$<18$ Years $(\mathrm{N}=30)$} & \multicolumn{3}{|c|}{$\geq 18$ Years $(N=14)$} \\
\hline & CGL $(N=15)$ & Controls $(N=15)$ & $\mathbf{P}$ & CGL $(\mathbf{N}=7)$ & Controls $(\mathbf{N}=\mathbf{7})$ & $\mathbf{P}$ \\
\hline LAVI, $\mathrm{mL} / \mathrm{m}^{2}$ & $26.0 \pm 7.7$ & $18.2 \pm 4.8$ & $<0.01 *$ & $27.4 \pm 8.4$ & $18.8 \pm 4.4$ & $0.04 *$ \\
\hline LVMI, $g / m^{2}$ ou 2,7 & $43.4 \pm 13.9$ & $27.3 \pm 7.7$ & $<0.01 *$ & $96.0 \pm 23.3$ & $54.3 \pm 10.3$ & $<0.01 *$ \\
\hline $\mathrm{EF}, \%$ & $70.9 \pm 4.5$ & $68.6 \pm 4.7$ & 0.33 & $66.1 \pm 5.1$ & $69 \pm 4.3$ & 0.34 \\
\hline LVDD, $\mathrm{mm} / \mathrm{m}^{2}$ & $39.0 \pm 11.8$ & $41.1 \pm 19.7$ & 0.52 & $29.3 \pm 1.5$ & $26.1 \pm 1.5$ & 0.64 \\
\hline LVDS, $\mathrm{mm} / \mathrm{m}^{2}$ & $23.2 \pm 7.2$ & $25.8 \pm 12.2$ & 0.26 & $17.9 \pm 1.7$ & $15.6 \pm 2.0$ & 0.41 \\
\hline $\mathrm{E}, \mathrm{ms}$ & $1.1 \pm 0.2$ & $I . I \pm 0.1$ & 0.87 & $0.8 \pm 0.1$ & $1.0 \pm 0.1$ & $0.02 *$ \\
\hline $\mathrm{A}, \mathrm{ms}$ & $0.5 \pm 0.1$ & $0.5 \pm 0.1$ & 0.16 & $0.5 \pm 0.1$ & $0.5 \pm 0.1$ & 0.84 \\
\hline E/A & $1.9 \pm 0.5$ & $2.2 \pm 0.7$ & 0.12 & $1.3 \pm 0.4$ & $1.8 \pm 0.4$ & 0.07 \\
\hline Es, ms & $12.3 \pm 2.7$ & $14.6 \pm 2.7$ & 0.23 & $9 \pm 1.9$ & $14.1 \pm 2.9$ & $<0.0 I^{*}$ \\
\hline $\mathrm{El}, \mathrm{ms}$ & $17.0 \pm 2.7$ & $18.6 \pm 2.7$ & 0.09 & $13.7 \pm 4.3$ & $18 \pm 1.0$ & $0.02 *$ \\
\hline $\mathrm{E} / \mathrm{E}^{\prime}$ & $7.4 \pm 1.9$ & $6.5 \pm 1.0$ & 0.16 & $7.7 \pm 2.3$ & $6.1 \pm 0.9$ & 0.17 \\
\hline
\end{tabular}

Notes: Data were described as mean and standard deviation. ${ }^{*} \mathrm{p}<0.05$ Mann-Whitney test.

Abbreviations: $n$, number of participants; ECHO, conventional echocardiogram parameters; LAVI, left atrial volume index; LVMI, left ventricular mass index; EF, left ventricular ejection fraction; LVDD, left ventricular end-diastolic diameter; LVDS, left ventricular end-systolic diameter; E, PW Doppler of early mitral filling; A, PW Doppler of later mitral filling; E/ A, ratio of E to A waves; Es, Tissue Doppler of septal mitral annulus velocity; El, Tissue Doppler of lateral mitral annulus velocity; E', mean Es-El; E/E', E/E' ratio.

Table 2 Prevalence of Abnormal Global Longitudinal Strain (GLS) Among 22 Patients with Congenital Generalized Lipodystrophy (CGL) Categorized by Age, According to Reference Ranges ${ }^{35}$

\begin{tabular}{|l|l|}
\hline $\begin{array}{l}\text { Age Group (Years- } \\
\text { Old) }\end{array}$ & $\begin{array}{l}\text { CGL/Total Patients with Abnormal } \\
\text { GLS (\%) }\end{array}$ \\
\hline $0-1$ & $0 / 1(0)$ \\
$2-9$ & $6 / 8(80)$ \\
$10-13$ & $1 / 3(33.3)$ \\
$|4-2|$ & $4 / 5(80)$ \\
$>21$ & $4 / 5(80)$ \\
\hline
\end{tabular}

strain (4C, 3C, and 2C chambers). This difference was not detected in apical segments (Table 3 ).

\section{Global Longitudinal Strain Compared to Conventional ECHO Parameters and}

\section{Clinical, Metabolic and Genetic}

\section{Characteristics of CGL Patients}

Among 15 CGL patients with abnormal GLS, 93.3\% (14/15) had hypertriglyceridemia, 93.3\% (14/15) had low HDL-c, $73.3 \%(11 / 15)$ had diabetes, 53.3\% (8/15) had hyperinsulinemia and 46\% (7/15) had hypercholesterolemia. Among noninsulinized patients, GLS was impaired in 62.5\% (5/8) with insulin resistance. Supplemental Table 1 summarizes the clinical, genetic and metabolic characteristics, conventional ECHO parameters, GLS and the medications used by 22 patients with CGL.

Diabetic CGL patients presented a higher prevalence of abnormal GLS than non-diabetic CGL patients, $73.3 \%(11 / 15)$ vs $57 \%(4 / 7)$, with a mean GLS of $-18.34 \%$ and $-21.35 \%$ in the later $(p=0.009)$.

Table 3 Segmental Longitudinal and Global Longitudinal Strain Data of 22 Patients with Congenital Generalized Lipodystrophy (CGL) and 22 Control Subjects

\begin{tabular}{|l|l|l|l|}
\hline Segmental LV & CGL & Control & P \\
\hline Basal inferior & $-17.6 \pm 6.2$ & $-21.6 \pm 3.0$ & $<0.0 I^{*}$ \\
Basal anterior & $-16.5 \pm 3.9$ & $-22.2 \pm 4.8$ & $<0.0 I^{*}$ \\
Basal septal & $-16.5 \pm 5.4$ & $-20.7 \pm 3.4$ & $<0.0 I^{*}$ \\
Basal lateral & $-12.5 \pm 7.3$ & $-21.2 \pm 4.5$ & $<0.0 I^{*}$ \\
Basal posterior & $-7.5 \pm 10.8$ & $-19.0 \pm 3.7$ & $<0.0 I^{*}$ \\
Basal anteroseptal & $-16.0 \pm 3.5$ & $-20.6 \pm 2.6$ & $<0.0 I^{*}$ \\
Mid lower & $-19.4 \pm 3.3$ & $-22.5 \pm 2.8$ & $<0.0 I^{*}$ \\
Mid anterior & $-19.6 \pm 4.1$ & $-23.2 \pm 3.7$ & $<0.0 I^{*}$ \\
Mid septal & $-19.1 \pm 3.8$ & $-22.7 \pm 3.6$ & $0.02^{*}$ \\
Mid lateral & $-16.7 \pm 2.7$ & $-22.5 \pm 4.1$ & $<0.0 I^{*}$ \\
Mid posterior & $-16.4 \pm 3.3$ & $-20.0 \pm 3.5$ & $<0.0 I^{*}$ \\
Mid anteroseptal & $-20.5 \pm 3.9$ & $-23.1 \pm 2.4$ & $0.0 I^{*}$ \\
Apical inferior & $-23.5 \pm 4.3$ & $-24.1 \pm 3.4$ & $0.6 I^{\prime}$ \\
Apical anterior & $-23.6 \pm 4.4$ & $-23.7 \pm 4.4$ & $0.9 I^{\prime}$ \\
Apical septal & $-24.4 \pm 3.7$ & $-24.1 \pm 4.1$ & $0.8 I^{\prime}$ \\
Apical lateral & $-23.3 \pm 4.4$ & $-22.4 \pm 4.5$ & 0.49 \\
Apical posterior & $-24.6 \pm 5.1$ & $-24.2 \pm 3.8$ & 0.92 \\
Apical anteroseptal & $-26.0 \pm 5.9$ & $-24.3 \pm 3.6$ & 0.48 \\
Aplax (A3c) & $-19.1 \pm 3.2$ & $-21.2 \pm 2.3$ & $0.0 I^{*}$ \\
A2c & $-19.7 \pm 3.3$ & $-22.7 \pm 2.3$ & $<0.0 I^{*}$ \\
A4c & $-18.7 \pm 3.6$ & $-22.2 \pm 2.9$ & $<0.0 I^{*}$ \\
GLS & $-19.2 \pm 2.4$ & $-22.1 \pm 1.7$ & $<0.0 I^{*}$ \\
\hline
\end{tabular}

Notes: Data were described as mean and standard deviation. ${ }^{*} \mathrm{p}<0.05$ MannWhitney test A.

Abbreviations: Aplax (A3c), apical 3-chamber longitudinal strain; A2c, apical 2-chamber longitudinal strain; A4c, apical 4-chamber longitudinal strain; GLS, global longitudinal strain. 
There was a moderate correlation between GLS and insulin levels, A1c, blood glucose and age. An inverse correlation was also noted between leptin levels and GLS in the 22 CGL patients (Table 4).

There was a weak correlation between HOMA-IR and GLS, but only 13 patients were not using exogenous insulin and included in this analysis $(r=0.39, \mathrm{p}=0.253)$.

A moderate correlation was found between GLS and EF $(\mathrm{r}=-0.49, \mathrm{p}=0.02)$ but none between age and $\mathrm{EF}(\mathrm{r}=-0.25$, $\mathrm{p}=0.2$ ). Any correlation among these echocardiographic parameters was observed in the control group.

\section{Discussion}

This is the first study to evaluate the heart function and morphology of a large sample of young CGL individuals using 2D-STE. This technique detected a high proportion of CGL patients with abnormal systolic function which was not detected with conventional ECHO.

Using the later we found an increased prevalence of $\mathrm{LVH}$, increased LAVI, LVDS and LVDD, and abnormal diastolic function, but no systolic dysfunction in our CGL patients. A cohort of 44 patients with congenital and acquired generalized lipodystrophy (29 CGL patients) assessed by conventional ECHO showed that 54.4\% (24/44) had hypertrophic cardiomyopathy, and $13.6 \%$ (6/44) presented characteristics of dilated cardiomyopathy. ${ }^{36}$ Other cross-sectional study of 22 asymptomatic Brazilian patients with CGL observed the high prevalence of cardiovascular abnormalities also using conventional ECHO-concentric LVH, excentric LVH and abnormal LV geometry, and diastolic dysfunction. ${ }^{3}$

Some of our patients presented valvar regurgitation with normal cusps associated with enlarged cardiac chambers suggesting that these abnormalities may be secondary to dilatation of the chambers. Cardiac dilatation but with

Table 4 Correlation Between Clinical and Metabolic Variables and Global Longitudinal Strain (GLS) in 22 Patients with Congenital Generalized Lipodystrophy

\begin{tabular}{|l|l|l|}
\hline Metabolic Variables & Rho & P \\
\hline Insulin (mU/mL) & $0.69^{*}$ & $0.024^{*}$ \\
Alc $(\%)$ & $0.57^{*}$ & $0.005^{*}$ \\
Leptin (ng/mL) & $-0.5 I^{*}$ & $0.005^{*}$ \\
Blood glucose (mg/dl) & $0.50^{*}$ & $0.018^{*}$ \\
Age (years) & 0.45 & $0.03^{*}$ \\
Triglycerides (mg/dl) & 0.36 & 0.098 \\
Total cholesterol (mg/dl) & 0.35 & 0.107 \\
HDL-c (mg/dl) & 0.31 & 0.147 \\
\hline
\end{tabular}

Note: ${ }^{*} \mathrm{p}<0.05$ Spearman correlation test. normal valve morphology was previously described in an autopsy study of CGL patients. ${ }^{37}$

Using 2D-STE we detected precocious left ventricular systolic dysfunction in a high proportion of CGL patients with normal systolic function when evaluated by conventional ECHO. The higher sensitivity of 2D-STE allows the detection of early abnormalities, due to the objective and quantitative assessment of global and regional myocardial function in all spatial directions. This imaging analysis through the frame-by-frame tracking of natural acoustic markers (speckles) has been shown clinical utility in several pathological conditions. ${ }^{7-11}$

Pathophysiological mechanisms of cardiomyopathy in lipodystrophies are not defined yet. ${ }^{3,5,36,37}$ Metabolic disorders, such as severe insulin resistance, high levels of triglycerides, diabetes mellitus and hypoleptinemia would be possible explanations. Our results support this hypothesis, based on the positive correlation of GLS with A1c, blood glucose and insulin, and the negative correlation with leptin levels.

Insulin resistance has been described as a cause of increased LV mass and heart growth. ${ }^{13}$ Insulin acts on insulin-like growth factor (IGF-1) receptors stimulating the stretching of myocardial fibers, causing changes in mass, diameters and, consequently, ventricular contraction. ${ }^{38,39}$ CGL patients usually present severe and early insulin resistance, as we found in our patients. The weak correlation between HOMA-IR and GLS may be explained due to the small number of non-insulinized patients.

In addition to the effect of insulin on cardiac fibers, high levels of serum triglycerides can lead to its accumulation in the heart, a condition referred to as "cardiac steatosis". 40-42 Hypertriglyceridemia was observed in $86.4 \%$ of our patients and in $93.3 \%$ of patients with altered GLS. This condition may lead to increased cardiac diameters, mass and volumes and LV dysfunction. ${ }^{42,43}$ Using magnetic resonance imaging Nelson et al showed a threefold accumulation of triglycerides in the myocardial cells of CGL patients compared to a control group, thus suggesting that cardiac impairment may also be caused by the deposition of triglycerides. $^{2}$

We also found a direct correlation between lower leptin levels and worse GLS in CGL patients. Leptin appears to influence the metabolism of triglycerides in myocytes. An experimental study demonstrated that leptin, acting at the central level, regulates TG cardiac deposition in adult rats with normal leptin sensitivity, increasing lipolysis and reducing lipogenesis. ${ }^{44}$ Thus, hypoleptinemia could lead 
to TG accumulation in myocardial cells and may partially explain the changes in cardiac morphology and ventricular function.

In addition to other metabolic disturbances that affect CGL patients, diabetes mellitus is one of the major risk factors for cardiovascular disorders, increasing the risk of coronary artery disease, cardiac autonomic neuropathy, diabetic cardiomyopathy and heart failure, accounting for $2 / 3$ of deaths in diabetic patients. ${ }^{45}$ Hyperglycemia accentuates oxidative stress and leads to the interstitial collagen deposition, fibrosis and apoptosis, which may result in ventricular systolic and diastolic dysfunction. ${ }^{46,47}$ Asymptomatic patients with metabolic syndrome and type 2 diabetes presented altered longitudinal strain, which might be an early finding of LV remodeling and subclinical cardiovascular disease. ${ }^{48,49}$ Diabetes mellitus was presented in $68.2 \%(15 / 22)$ of our CGL patients, where $73.3 \%$ of them presented altered GLS, versus $57 \%$ in the group of CGL patients without diabetes.

Diabetes and dyslipidemia are risk factors for atherosclerosis, which also triggers LV systolic and diastolic dysfunction. Postmortem findings in CGL patients including atheromatous plaques with stenosis grade of $20 \%$ in left and right coronary arteries were previously described. ${ }^{50}$ Autopsy studies also revealed mild thickening of small intramural coronary arteries in affected patients. ${ }^{51}$ A 17-year-old CGL girl with acute myocardial infarction and angiographically normal coronary arteries was reported. ${ }^{12}$ Although this study did not directly assess coronary circulation, our patients have several risk factors for early coronary atherosclerosis. Thus, we may speculate that subclinical coronary disease may be involved in these abnormalities detected by 2D-STE.

In our study we found impairment of the longitudinal strain in basal and mid-cavity segments of LV, but not in apical segments in CGL patients compared to the control group. A plausible hypothesis for these findings is the higher amount of longitudinal myocardial fibers in the apical segments, which favors cardiac contraction and the delay of the involvement of this region. ${ }^{52}$ Our findings were similar to described by Phellan et al, ${ }^{53}$ who showed early impairment of the longitudinal strain of the mid-cavity and basal segments in relation to the apical segments in patients with cardiac amyloidosis, a deposit disease. $^{54}$

We observed a higher prevalence of subclinical systolic dysfunction in CGL2 patients $(83.3 \%)$ compared to CGL1 (50.0\%) using 2D-STE. These findings are in accordance with previous studies that showed a high prevalence of cardiac impairment in CGL2. ${ }^{36,55,56}$ This subtype has more pronounced metabolic abnormalities than CGL1 due to a more intense loss of functional adipocytes. ${ }^{19}$

This is the first study to detect cardiac alterations using 2D-STE in patients with this rare disease. However, the relatively small number of patients and the wide range of age attenuate the strength of our findings. Nevertheless, our series is one of the largest of CGL in Brazil. This is also a cross-sectional study, which carried out at one time point and gives no indication of the time sequence of between exposure and outcome.

\section{Conclusion}

The 2D-STE revealed precocious left ventricular systolic dysfunction, even with a normal systolic function when evaluated by conventional ECHO in a young population with CGL. Early exposure to hypoleptinemia and/or insulin resistance even before hyperglycemia must be involved in the myocardial damage in these patients.

Early detection of cardiac abnormalities in young CGL patients using 2D-STE may support a more effective treatment to prevent the high morbidity and mortality usually found in this disorder.

\section{Abbreviations}

2C, apical 2-chamber longitudinal strain; 2D-STE, Twodimensional speckle-tracking echocardiography; 3C, apical 3-chamber longitudinal strain; 4C, apical 4-chamber longitudinal strain; A1c, glycohemoglobin A1c; A, Pulsedwave Doppler of later mitral filling; AGPAT2, 1-acylglycerol-3-phosphate O-acyltransferase 2; BRAZLIPO, Brazilian Group for the Study of Inherited and Acquired Lipodystrophies; BSA, body surface area; BSCL2, Bernardinelli-Seip congenital lipodystrophy type 2 protein; CGL1, congenital generalized lipodystrophy type 1; CGL2, congenital generalized lipodystrophy type 2; CGL, Congenital generalized lipodystrophy; DTI, pulsed-wave Doppler tissue imaging; E/A, ratio of $\mathrm{E}$ to A waves; $\mathrm{E}$, Pulsed-wave Doppler of early mitral filling; E', mean of Tissue Doppler of lateral mitral annulus velocity and Tissue Doppler of septal mitral annulus velocity; ECHO, standard conventional echocardiography; EF, ejection fraction; El, Tissue Doppler of lateral mitral annulus velocity; Es, Tissue Doppler of septal mitral annulus velocity; GLS, global longitudinal strain; HOMA-IR, homeostasis model assessment of insulin resistance; IGF-1, insulin-like growth factor; LAVI, left atrial volume index; LV, left ventricle; LVDD, left ventricular diastolic diameter; LVDS, left ventricular systolic diameter; LVEF, Left 
ventricle ejection fraction; LVH, left ventricular hypertrophy; LVMI, LV mass index; PW, Pulsed-wave Doppler; SPSS, Statistical Package for the Social Sciences; STROBE, Strengthening the Reporting of Observational Studies in Epidemiology.

\section{Ethics Approval and Consent to Participate}

This study was performed in accordance with the Declaration of Helsinki and was approved by the University Hospital Walter Cantídio Ethics Committee, Fortaleza, Ceara, Brazil ( $n^{\circ}$ 1.916.387). All the patients and their families gave formal consent to participate in the study by signing the free informed consent form prior to their inclusion.

\section{Data Sharing Statement}

The datasets used and analyzed during the current study are available from the corresponding author on reasonable request.

\section{Author Contributions}

All authors contributed to data analysis, drafting and revising the article, gave final approval of the version to be published, and agree to be accountable for all aspects of the work.

\section{Disclosure}

Prof. Dr. Renan Magalhães Montenegro Junior report grants from Aegerion Pharmaceuticals during the conduct of the study. The authors report no other conflicts of interest in this work.

\section{References}

1. Garg A. Acquired And Inherited Lipodystrophies. $N$ Engl $J$ Med. 2004;350:1220-1234.

2. Nelson MD, Victor RG, Szczepaniak EW, Simha V, Garg A, Szczepaniak LS. Cardiac steatosis and left ventricular hypertrophy in patients with generalized lipodystrophy as determined by magnetic resonance spectroscopy and imaging. Am J Cardiol. 2013;112 (7):1019-1024. doi:10.1016/j.amjcard.2013.05.036

3. Rego AGD. Anormalidades cardiovasculares e metabólicas em pacientes com a síndrome de Berardinelli-Seip. Arq Bras Cardiol. 2009.

4. Brown RJ, Araujo-Vilar D, Cheung PT, et al. The diagnosis and management of lipodystrophy syndromes: a multi-society practice guideline. $J$ Clin Endocrinol Metab. 2016;101(12):4500-4511. doi:10.1210/jc.2016-2466

5. Hussain I, Patni N, Garg A. Lipodystrophies, dyslipidaemias and atherosclerotic cardiovascular disease. Pathology. 2018;51(2): 202-12.
6. Amundsen BH, Helle-Valle T, Edvardsen T, et al. Noninvasive myocardial strain measurement by speckle tracking echocardiography: validation against sonomicrometry and tagged magnetic resonance imaging. J Am Coll Cardiol. 2006;47(4):789-793. doi:10.1016/j. jacc.2005.10.040

7. Sitia S, Tomasoni L, Turiel M. Speckle tracking echocardiography: a new approach to myocardial function. World J Cardiol. 2010;2(1):1. doi:10.4330/wjc.v2.i1.1

8. Leitman M, Lysyansky P, Sidenko S, et al. Two-dimensional strain-a novel software for real-time quantitative echocardiographic assessment of myocardial function. $J$ Am Soc Echocardiogr. 2004;17 (10):1021-1029. doi:10.1016/j.echo.2004.06.019

9. Reisner SA, Lysyansky P, Agmon Y, Mutlak D, Lessick J, Friedman Z. Global longitudinal strain: a novel index of left ventricular systolic function. J Am Soc Echocardiogr. 2004;17(6):630-633. doi:10.1016/ j.echo.2004.02.011

10. Shah AM, Solomon SD. Myocardial deformation imaging: current status and future directions. Circulation. 2012;125(2):e244-e248. doi:10.1161/CIRCULATIONAHA.111.086348

11. Mondillo S, Galderisi M, Mele D, et al. Speckle-tracking echocardiography: a new technique for assessing myocardial function. $J$ Ultrasound Med. 2011;30(1):71-83. doi:10.7863/jum.2011.30.1.71

12. Khalife WI, Mourtada MC, Khalil J. Dilated cardiomyopathy and myocardial infarction secondary to congenital generalized lipodystrophy. Texas Hear Inst J. 2008;35(2):196.

13. Bhayana S, Siu VM, Joubert GI, Clarson CL, Cao H, Hegele RA. Cardiomyopathy in congenital complete lipodystrophy. Clin Genet. 2002;61(4):283-287. doi:10.1034/j.1399-0004.2002.610407.x

14. Scatteia A, Pagano C, Pascale C, et al. Asymmetric hypertrophic cardiomyopathy in generalized lipodystrophy. Int $J$ Cardiol. 2016;202:724-725. doi:10.1016/j.ijcard.2015.10.032

15. Friguls B, Coroleu W, Del Alcazar R, Hilbert P, Van Maldergem L, Pintos-Morell G. Severe cardiac phenotype of Berardinelli-Seip congenital lipodystrophy in an infant with homozygous E189X BSCL2 mutation. Eur J Med Genet. 2009;52(1):14-16. doi:10.1016/j. ejmg.2008.10.006

16. Viégas RFM, Diniz RVZ, Viégas TMRF, Lira F, Bezerra E, de Almeida DR. Cardiac involvement in total generalized lipodystrophy (Berardinelli-Seip syndrome). Arq Bras Cardiol. 2000;75(3):246248. doi:10.1590/S0066-782X2000000900006

17. Rajab A, Straub V, McCann LJ, et al. Fatal cardiac arrhythmia and long-QT syndrome in a new form of congenital generalized lipodystrophy with muscle rippling (CGL4) due to PTRF-CAVIN mutations. PLoS Genet. 2010;6(3):e1000874. doi:10.1371/journal. pgen. 1000874

18. Von Elm E, Altman DG, Egger M, Pocock SJ, Gøtzsche PC, Vandenbroucke JP. The Strengthening the Reporting of Observational Studies in Epidemiology (STROBE) statement: guidelines for reporting observational studies. Ann Intern Med. 2007;147 (8):573-577. doi:10.7326/0003-4819-147-8-200710160-00010

19. Patni N, Garg A. Congenital generalized lipodystrophies - new insights into metabolic dysfunction. Nat Publ Gr. 2015. doi:10.1038/nrendo.2015.123

20. Matthews DR, Hosker JP, Rudenski AS, Naylor BA, Treacher DF, Turner RC. Homeostasis model assessment: insulin resistance and $\beta$ cell function from fasting plasma glucose and insulin concentrations in man. Diabetologia. 1985;28(7):412-419. doi:10.1007/BF00280883

21. Fu M, Kazlauskaite R, de Paiva Baracho MF, et al. Mutations in Gng3lg and AGPAT2 in Berardinelli-Seip congenital lipodystrophy and Brunzell syndrome: phenotype variability suggests important modifier effects. J Clin Endocrinol Metab. 2004;89(6):2916-2922. doi:10.1210/jc.2003-030485

22. Tajik AJ, Seward JB, Hagler DJ, Mair DD, Lie JT. Two-dimensional real-time ultrasonic imaging of the heart and great vessels. Technique, image orientation, structure identification, and validation. Mayo Clin Proc. 1978;53.:271-303. 
23. Edwards WD, Tajik AJ, Seward JB. Standardized nomenclature and anatomic basis for regional tomographic analysis of the heart. Mayo Clin Proc. 1981;56.:479-497.

24. Bansal RC, Tajik AJ, Seward JB, Offord KP. Feasibility of detailed two-dimensional echocardiographic examination in adults. Prospective study of 200 patients. Mayo Clin Proc. 1980;55.:291308.

25. Henry WL, DeMaria A, Gramiak R, et al. Report of the American Society of Echocardiography Committee on nomenclature and standards in two-dimensional echocardiography. Circulation. 1980;62 (2):212-217. doi:10.1161/01.CIR.62.2.212

26. Lopez L, Colan SD, Frommelt PC, et al. Recomendações para os médicos de quantificação durante a realização do ecocardiograma pediátrico: relatório escrito pelo grupo da Sociedade Americana de Ecocardiografia e do Conselho em Cardiopatias Congênitas. $A B C$ Imagem Cardiovasc. 2014;27(3):151-183.

27. Lang RM, Bierig M, Devereux RB, et al. Recommendations for chamber quantification. Eur J Echocardiogr. 2006;7(2):79-108. doi:10.1016/j.euje.2005.12.014

28. Sluysmans T, Colan SD. Theoretical and empirical derivation of cardiovascular allometric relationships in children. J Appl Physiol. 2005;99(2):445-457. doi:10.1152/japplphysiol.01144.2004

29. Nagueh SF, Smiseth OA, Appleton CP, et al. Recommendations for the evaluation of left ventricular diastolic function by echocardiography: an update from the American Society of Echocardiography and the European Association of Cardiovascular Imaging. Eur $J$ Echocardiogr. 2016;17(12):1321-1360.

30. Lang RM, Badano LP, Mor-Avi V, et al. Recommendations for cardiac chamber quantification by echocardiography in adults: an update from the American Society of Echocardiography and the European Association of Cardiovascular Imaging. Eur Heart J Cardiovascular Imaging. 2015;16(3):233-271. doi:10.1093/ehjci/ jev014

31. Lima MSM. Estudo Da Dinâmica De Contração Do Ventrículo Esquerdo Pela Técnica De Speckle Tracking Em Doença De Chagas. 2013.

32. Mor-Avi V, Lang RM, Badano LP, et al. Current and evolving echocardiographic techniques for the quantitative evaluation of cardiac mechanics: ASE/EAE consensus statement on methodology and indications endorsed by the Japanese Society of Echocardiography. Eur J Echocardiogr. 2011;12(3):167-205. doi:10.1093/ejechocard/ jer021

33. Artis NJ, Oxborough DL, Williams G, Pepper CB, Tan LB. Twodimensional strain imaging: a new echocardiographic advance with research and clinical applications. Int J Cardiol. 2008;123(3):240248. doi:10.1016/j.ijcard.2007.02.046

34. Dandel M, Lehmkuhl H, Knosalla C, Suramelashvili N, Hetzer R. Strain and strain rate imaging by echocardiography-basic concepts and clinical applicability. Curr Cardiol Rev. 2009;5(2):133-148. doi:10.2174/157340309788166642

35. Levy PT, Machefsky A, Sanchez AA, et al. Reference ranges of left ventricular strain measures by two-dimensional speckle-tracking echocardiography in children: a systematic review and meta-analysis. $J$ Am Soc Echocardiogr. 2016;29(3):209-225. doi:10.1016/j. echo.2015.11.016

36. Lupsa BC, Sachdev V, Lungu AO, Rosing DR, Gorden P. Cardiomyopathy in congenital and acquired generalized lipodystrophy: a clinical assessment. Medicine (Baltimore). 2010;89(4):245. doi:10.1097/MD.0b013e3181e9442f

37. Bjørnstad PG, Foerster A, Ihlen H. Cardiac findings in generalized lipodystrophy. Acta Pcediatrica. 1996;85:39-43. doi:10.1111/ apa.1996.85.issue-s413

38. Klar A, Brand A, Hurvitz H, Gross-Kieselstein E, Branski D. Cardiomyopathy in lipodystrophy and the specificity spillover hypothesis. Isr J Med Sci. 1993;29(1):50.
39. Geffner ME, Santulli TV, Kaplan SA. Hypertrophic cardiomyopathy in total lipodystrophy: insulin action in the face of insulin resistance? $J$ Pediatr. 1987;110(1):161. doi:10.1016/S0022-3476(87)80317-7

40. Glenn DJ, Wang F, Nishimoto M, et al. A murine model of isolated cardiac steatosis leads to cardiomyopathy. Hypertension. 2011;57 (2):216-222. doi:10.1161/HYPERTENSIONAHA.110.160655

41. Lee Y, Naseem RH, Duplomb L, et al. Hyperleptinemia prevents lipotoxic cardiomyopathy in acyl CoA synthase transgenic mice. Proc Natl Acad Sci. 2004;101(37):13624-13629. doi:10.1073/ pnas.0405499101

42. Szczepaniak LS, Victor RG, Orci L, Unger RH. Forgotten but not gone: the rediscovery of fatty heart, the most common unrecognized disease in America. Circ Res. 2007;101(8):759-767. doi:10.1161/ CIRCRESAHA.107.160457

43. Pilz S, März W. Free fatty acids as a cardiovascular risk factor. Clin Chem Lab Med. 2008;46(4):429-434. doi:10.1515/CCLM.2008.118

44. Mora C, Pintado C, Rubio B, et al. Central leptin regulates heart lipid content by selectively increasing PPAR $\beta / \delta$ expression. $J$ Endocrinol. 2018;236(1):43-56. doi:10.1530/JOE-17-0554

45. Pappachan JM, Varughese GI, Sriraman R, Arunagirinathan G. Diabetic cardiomyopathy: pathophysiology, diagnostic evaluation and management. World J Diabetes. 2013;4(5):177. doi:10.4239/ wjd.v4.i5.177

46. Hensel KO, Grimmer F, Roskopf M, Jenke AC, Wirth S, Heusch A. Subclinical alterations of cardiac mechanics present early in the course of pediatric type 1 diabetes mellitus: a prospective blinded speckle tracking stress echocardiography study. J Diabetes Res. 2016;2016.

47. Zoroufian A, Razmi T, Taghavi-Shavazi M, Lotfi-Tokaldany M, Jalali A. Evaluation of subclinical left ventricular dysfunction in diabetic patients: longitudinal strain velocities and left ventricular dyssynchrony by two-dimensional speckle tracking echocardiography study. Echocardiography. 2014;31(4):456-463. doi:10.1111/ echo. 12389

48. Ernande L, Bergerot C, Girerd N, et al. Longitudinal myocardial strain alteration is associated with left ventricular remodeling in asymptomatic patients with type 2 diabetes mellitus. J Am Soc Echocardiogr. 2014;27(5):479-488. doi:10.1016/j.echo.2014.01.001

49. Moaref A, Faraji M, Tahamtan M. Subclinical left ventricular systolic dysfunction in patients with metabolic syndrome: a case-control study using two-dimensional speckle tracking echocardiography. ARYA Atheroscler. 2016;12(6):254-258.

50. Chandalia M, Garg A, Vuitch F, Nizzi F. Postmortem findings in congenital generalized lipodystrophy. J Clin Endocrinol Metab. 1995;80(10):3077-3081. doi:10.1210/jcem.80.10.7559900

51. Sanon VP, Handelsman Y, Pham SV, Chilton R. Cardiac manifestations of congenital generalized lipodystrophy. Clin Diabetes. 2016;34 (4):181-186. doi:10.2337/cd16-0002

52. Del Castillo JM, Herszkowicz N, Ferreira C. Speckle tracking-a contratilidade miocárdica em sintonia fina. Rev Bras Ecocardiogr Imagem Cardiovasc. 2010;23(3):46-54.

53. Phelan D, Collier $\mathrm{P}$, Thavendiranathan $\mathrm{P}$, et al. Relative apical sparing of longitudinal strain using two-dimensional speckle-tracking echocardiography is both sensitive and specific for the diagnosis of cardiac amyloidosis. Heart. 2012;98(19):1442-1448. doi:10.1136/ heartjnl-2012-302353

54. Desai HV, Aronow WS, Peterson SJ, Frishman WH. Cardiac amyloidosis: approaches to diagnosis and management. Cardiol Rev. 2010;18(1):1-11. doi:10.1097/CRD.0b013e3181bdba8f

55. Van Maldergem L, Magre J, Khallouf TE, et al. Genotype-phenotype relationships in Berardinelli-Seip congenital lipodystrophy. $J$ Med Genet. 2002;39(10):722-733. doi:10.1136/jmg.39.10.722

56. Agarwal AK, Simha V, Oral EA, et al. Phenotypic and genetic heterogeneity in congenital generalized lipodystrophy. $J$ Clin Endocrinol Metab. 2003;88(10):4840-4847. doi:10.1210/jc.2003030855 


\section{Publish your work in this journal}

Diabetes, Metabolic Syndrome and Obesity: Targets and Therapy is an international, peer-reviewed open-access journal committed to the rapid publication of the latest laboratory and clinical findings in the fields of diabetes, metabolic syndrome and obesity research. Original research, review, case reports, hypothesis formation, expert opinion and commentaries are all considered for publication. The manuscript management system is completely online and includes a very quick and fair peer-review system, which is all easy to use. Visit http://www.dovepress.com/testimonials.php to read real quotes from published authors.

Submit your manuscript here: https://www.dovepress.com/diabetes-metabolic-syndrome-and-obesity-targets-and-therapy-journal 